\title{
A VESTAL E O IMANE: DESDOBRAMENTOS LITERÁRIOS DO FEMININO NARCÍSICO E CONFESSIONAL NA OBRA E NA BIOGRAFIA DE FLORBELA ESPANCA, ESCRITORA MODERNISTA PORTUGUESA
}

Zilda de Oliveira Freitas

Resumo: Este artigo apresenta uma análise crítica e reflexiva sobre a produção literária e a biografia da escritora portuguesa Florbela Espanca, a partir da representação do feminino como uma vestal e da heroicização do masculino como um imane, no contexto modernista europeu, considerando as reminiscências do espectro mítico narcísico. Fundamenta-se teoricamente o presente texto em ponderações sobre o modernismo lusitano, publicadas por estudiosos como A. Amora e D. Vila Maior, os mitólogos M. Eliade e T. Bulfinch, além de pesquisadores e biógrafos, como A. Bessa Luís, Maria L. Dal Farra, N. Correia e outros leitores da obra florbeliana.

Palavras-chave: Modernismo. Literatura. Narcisismo. Florbela Espanca.

Abstract: This article presents a critical and reflective analysis of the literary production and biography of the portuguese writer Florbela Espanca, based on the representation of the feminine as a vestal and the heroicization of the masculine as a imane, in the european modernist context, considering the reminiscences of the mythical spectrum narcissistic. The present text is theoretically based on considerations about lusitanian modernism, published by researchers such as A. Amora and D. Vila Maior, the mythologists M. Eliade and T. Bulfinch, as well as researchers and biographers, such as A. Bessa Luís, Maria L. Dal Farra, N. Correia and other readers of the florbelian work. Keywords: Modernism. Literature. Narcissism. Florbela Espanca.

\section{INTRODUÇÃO}

A obra da escritora portuguesa Florbela Espanca vem sendo muito divulgada ao público brasileiro nas últimas décadas. Ressaltarei a contribuição do cantor brasileiro 
Raimundo Fagner, que em 1981 musicou poemas em seu álbum Traduzir-se, comercializado com sucesso na Europa e América Latina. Encontra-se na primeira música do álbum os versos de "Fanatismo"1, soneto de Florbela Espanca, publicado em 1923, no Livro de Sóror Saudade. A excelente recepção incentivou o cantor a musicalizar no ano seguinte outros poemas florbelianos, como "Tortura2" e "Fumo". Em 2000, Fagner converteu em música também o "Soneto I/Chama quente"4. Do Livro de Sóror Saudade, Fagner gravou ainda "Frieza", soneto de Florbela Espanca cantado em dueto com Amelinha. Em outro dueto, desta vez com a cantora espanhola Ana Belén, Fagner gravou "Impossível", último soneto florbeliano incluído no Livro de Mágoas. A partir do sucesso de Fagner e da aceitação pelo público, nos anos seguintes Zeca Baleiro ${ }^{5}$, Zé Ramalho ${ }^{6}$, Cauby Peixoto ${ }^{7}$ e diversos outros cantores brasileiros regravaram os versos de Florbela Espanca musicalizados por Fagner ${ }^{8}$.

\footnotetext{
1 Empregaremos itálico para título de livros e aspas baixas para contos e poemas.

2 Publicado por Florbela Espanca no Livro de Mágoas, em 1919.

3 Soneto que também integra a obra supracitada Livro de Sóror Saudade, de 1923.

4 Publicado por Florbela Espanca na obra Charneca em Flor em 1931, mas Fagner incluiu o título "Chama quente".

5 Dueto com Fagner em "Fanatismo".

6 Emprestou sua voz a "Fanatismo".

7 Interpretou o soneto florbeliano "Tortura".

8 As músicas mencionadas estão disponíveis no YouTube.
} 
No entanto, a produção literária de Florbela Espanca não se compõe apenas de sonetos. Publicou contos, cartas, diário e uma vasta obra em quadras e outros formatos poéticos. Disponíveis em antologias organizadas por M. da Graça O. Martins, Maria Lúcia Dal Farra e muitos outros, a obra florbeliana motivou leituras poéticas como fazem Natália Correia e Agustina Bessa Luís, além de cuidadosas pesquisas acadêmicas, que deram origem a dissertações e teses sobre Florbela Espanca, publicadas em vários países nas últimas décadas.

Utilizaremos algumas destas contribuições para fundamentar teoricamente nossa leitura pessoal sobre a autora, a partir da construção de um par antitético entre a vestal e o imane, para buscar surpreender os desdobramentos literários do feminino narcísico e confessional na obra de Florbela Espanca, escritora, diva e personagem do cenário modernista europeu.

\section{A VESTAL: INTANGÍVEL, SEDUTORA E DRAMÁTICA}

A vestal é uma sacerdotisa que (re)vela e preserva em si o fogo sagrado feminino da deusa romana Vesta9. Desejada por Apolo, Netuno e tantos outros, Vesta implorou ao pai

9 Correspondente a Héstia na mitologia grega. Etimologicamente a palavra vestal teria a origem latina vestalis, aquela que serve a Vesta: "Em seu templo, ardia constantemente um fogo sagrado, sob a guarda de seis sacerdotisas virgens, as Vestais" (BULFINCH, 2000, p. 17). 
Júpiter que resguardasse sua castidade. Portanto, podemos interpretar no mito que a deusa recusa à gratificação sexual convencionada, pois recusa a entrega do seu corpo a deuses ou a homens. Neste sentido, é uma ressonância do mito de Narciso10, que veremos adiante. A vestal, mulher labareda que serve a Vesta, não serve a ninguém mais além de si mesma e suas iguais, no espelhamento narcísico do sujeito desejante e insatisfeito.

A escritora Florbela Espanca pode ser compreendida como uma vestal desmedida e teatralizada, que, de acordo com a sua biógrafa Agustina Bessa Luís, é uma mulher "introvertida, quase diremos com as características do tipo mais parcialmente descrito. Como acontece com este carácter, a nota humana é muitas vezes desmesurada e irracional" (BESSA LUIS, 1984, p. 12).

Muitos leem a obra florbeliana como depoimento e registro psíquico da autora enquanto sujeito desejante. A intricada "relação arte-vida" (VILA MAIOR, 1996, p. 191), que constitui a literatura confessional, pode nos conduzir ao entendimento da sua produção literária como essencialmente

10 Para a compreensão do mito de Narciso na literatura e na sociedade modernista, retomamos aqui as reflexões de Raïsa Cavalcanti: "O termo narcisismo foi inicialmente usado por Paul Nacke, em 1899 para descrever um estado de auto-erotismo no qual a pessoa toma o próprio corpo como objeto de interesse e de gratificação sexual. [...] Narciso está exatamente na fronteira do plano arquetípico para o plano pessoal. Ele simboliza a passagem da vida arquetípica para a vida pessoal histórica" (CAVALCANTI, 2003, 29). 
autobiográfica e delirante, em trechos como os seguintes: “...sempre a Florbela, a Florbela, a Florbela! Gostaria de endoidecer" (ESPANCA, 1982, p. 45); ou "Eu seria outra, outra, outra!" (ESPANCA, 1982, p. 45-46). Em tom confessional, escritos predominantemente em primeira pessoa e em discurso autoral livre, os textos de Florbela Espanca podem se assemelhar ao pensamento do escritor modernista português Fernando Pessoa, quando reflete sobre a sua performance de poeta solitária e neurastênica, como seu contemporâneo: "Viver é não saber que se vive. Procurar o sentido da vida, sem mesmo saber se algum sentido tem, é tarefa de poetas e neurasténicos" (ESPANCA, 1982, p. 53.). E mais claramente: "Está escrito que hei-de ser sempre a mesma eterna isolada... Porquê?" (ESPANCA, 1982, p. 57).

Entretanto, a obra florbeliana não se apoia na produção literária de Fernando Pessoa ou de quem quer que seja. Gigante que sobe em seus próprios ombros, refletidos narcisicamente diante de si, através do seu modo independente de ser e ver sua contribuição para a literatura modernista portuguesa, a autora se irmana aos melhores escritores do século XX, como uma vestal entre vestais. Um estudo completo sobre Fernando Pessoa e Florbela Espanca no cenário das vanguardas lusitanas deveria ser realizado. 
Ressaltamos que a ficcionalização da realidade pode ser o elo reminiscente entre ambos, pois o alheamento de si e, sobretudo, no processo de interação social fragiliza e estilhaça o sujeito modernista, que encontra no gesto da escrita a possibilidade de construir ou reconstruir a realidade à sua maneira, como observa Paes:

Pelo seu poder vicariante, a ficção tem inclusive um efeito pedagógico sobre nós quando mostra, num exemplário tão rico quanto o da própria vida, a multiplicidade de dilemas e opções, de possibilidades e limites de ação com que se defronta a cada passo, múltipla também, conquanto una, a condição humana, promovendo com isso, para usar a frase flaubertiana, uma espécie de educação sentimental nossa para a vida fora das páginas do livro. (1990. p. 7)

Se a ficção promove a educação sentimental para além da literatura e "A arte não tem que copiar o mundo, mas recriá-Io" (MALRAUX apud BARROSO, 1998, p. 17), é compreensível que muitos entendam a obra florbeliana como a autobiografia de uma vestal, súdita apenas de si mesma e de outras iguais, em textos-espelhos, autobiográficos e narcísicos.

Lembra-nos Luis Alberto Brandão que "o texto literário [...] é tão mais vinculado à realidade quanto mais exercita sua autonomia em relação a ela; que é tão mais penetrante e 
abrangente quanto mais aberto e especulativo" (BRANDÃO, 2005, p. 9). Afirma ainda o autor que "O caráter paradoxal da experiência literária se explica pelo fato de esta tornar possível o questionamento da oposição entre real e ficcional" (BRANDÃO, 2005, p. 9-10). Parece-nos ser extremamente sutil a fronteira entre real e ficcional no que se refere à travessia literária de Florbela Espanca ${ }^{11}$, o que muitas vezes lhe confere o status de personagem ${ }^{12}$ ou persona literária ${ }^{13}$, paralelo à condição de mulher e escritora ${ }^{14}$. No excerto abaixo, Martins destaca a identificação absoluta de Florbela Espanca com sua obra:

"Isto o confirmam a vida e a obra de uma das figuras mais complexas e igualmente fascinantes das letras portuguesas: Florbela Espanca, sobre a qual se afigura óbvia a constatação de que os limites entre o mundo por si recriado, em verso e em prosa, e a sua vida são bastante ténues, se não arbitrários. Quer isto dizer que os dois planos não somente se interseccionam, mas, acima de tudo, se (con)fundem [...]. E, fundamentalmente, Florbela é a sua obra, num acto de identificação absoluta. (MARTINS, 1990, p. 5)

11 De acordo com Agustina Bessa Luís, "Para ler a prosa de Florbela Espanca é preciso conhecer a mulher" (BESSA LUÍS, 1981, p. 16).

12 Personagem, persona ou entes ficcionais, como conceitua Brait (2006, p. 40).

13 Leia-se a persona literária de Florbela Espanca em Dal Farra (2007, p. 41).

14 "Uma das conclusões possíveis sobre esta problemática é a de que se a obra de arte é ficcional, não menos verdade é, no entanto, que o mundo sugerido pelo artista é uma recriação pessoal e individualizante do real em que aquele se insere e é uma projecção do seu próprio ideário de valores e de conceitos" (MARTINS, 1990, p. 5). 
Esclarece Amora que "Todos nós, que não somos escritores, temos a ideia de que um poeta [...] é uma pessoa, não apenas diferente de nós, pelas virtualidades criativas, mas também sui generis ou incomum no comportamento" (AMORA, 1970, p. 111). Indubitavelmente o comportamento social da mulher Florbela Espanca parece sui generis ou incomum, sobretudo teatralizado, pois apresenta o seu corpo que "só é construído para ser visto. É teatralizado ao mais alto grau" (MAFFESOLI, 1996, p. 38). Psicologicamente um complexo quadro exibicionista e depressivo ${ }^{15}$ parece justificar os desdobramentos literários de Florbela Espanca, na busca pela construção de uma persona mítica, dramática como uma diva ${ }^{16}$, o que é facilmente perceptível a seus contemporâneos, biógrafos e leitores. Acredita M. da Graça Orge Martins que Florbela Espanca dramatiza seus males na vida e na obra, para atrair a atenção e seduzir seus interlocutores:

Florbela aproveita e exagera os efeitos das maleitas que a afligem como forma de atrair sobre si todas as atenções, ao ponto de os médicos serem as companhias por si privilegiadas, sendo que eles próprios alimentam e dão cobertura às suas manias e fobias. Alguns estudiosos florbelianos sustentam a tese de que o conto "Amor

15 Florbela Espanca sofria de uma debilitante e insistente depressão nervosa (MARTINS, 1990, p. 7).

16 Escreve Natália Correia: "Bela estende-se na chaise-longue dos seus quebrantos de diva dos versos" (CORREIA, 1982, p. 10). 
de outrora" teria como referente o relacionamento da autora com um dos seus muitos médicos. (MARTINS, 1990, p. 7)

No Prefácio à obra florbeliana Diário do último ano, Natália Correia destaca o comportamento mimético e dramático de Florbela Espanca como uma vestal virgem, pois "Os adereços de sua tragédia tém a futilidade das paixões vãs e fugidias que a consomem" (CORREIA, N., 1982, p. 9). A autora comenta a aparência cênica de Florbela Espanca ${ }^{17}$, evidenciada na "barateza das jóias de um guarda-roupa teatral: as pérolas do colar com que, nos lances dramáticos da sua sede de ser única, Bela aperta" (CORREIA, 1982, p. 9-10. Mantivemos a grafia original em ambas as citações). Ainda mais claramente, escreve Natália Correia que "A teatralidade de Florbela é a interpretação genial deste mistério feminino que se desgarra na gesticulação dramática da poetisa" (CORREIA, 1982, p. 11) $)^{18}$.

A imagem projetada narcisicamente por Florbela Espanca é de uma sacerdotisa, diva e personagem das histórias

17 Agustina Bessa Luís denomina "culto do trajo" à teatralidade na aparência de Florbela Espanca: “Há em Florbela um certo culto do trajo: as pérolas, os chapéus, as peles. E não era vaidade. Mas o que são os vaidosos senão os que temem a sua nudez? Os que evitam o retrato da alma para não Ihe descobrir tormento e debilidade?" (BESSA LUÍS, 1981, p. 12).

18 Sobre a estética da teatralidade na obra florbeliana, Renata Junqueira escreve: “E uma análise cuidadosa do aparato das máscaras, das poses e dos artifícios retóricos na obra de Florbela pode demonstrar que tanto a sua poesia quanto a sua prosa se revestem daquela teatralidade que constitui uma das mais importantes características dos movimentos de vanguarda no princípio do século XX" (JUNQUEIRA, 2003, p. 18). 
que ela própria narra. E ainda: na leitura da mencionada prefaciadora, Florbela Espanca é uma atriz das cenas criadas e recriadas incessantemente ${ }^{19}$ por ela mesma, para atrair a atenção de todos e seduzir o absoluto: "Desprendese deste diário o aroma das flores e perfumes do camarim em que a atriz se prepara para entrar na última cena: a morte. Bela enfeita-se para seduzir o absoluto (CORREIA, 1982, p. 11). Fato é que o Diário do último ano expõe na prosa o que já se reconhecia na obra poética de Florbela Espanca: a expressão literária de uma pretensa virgem inatingível, narcísica e autora de uma lancinante obra confessional, representante modernista que se legitima como sacerdotisa do Eterno feminino ${ }^{20}$.

Refletiremos no próximo tópico sobre os desdobramentos literários do bestial masculino, heroicizado nas figuras do pai, do irmão Apeles, dos maridos e dos amantes de Florbela Espanca, opondo-se assim o masculino devorador da sua casa-corpo à sacerdotisa mítica e narcísica.

19 Ressalta Natália Correia que "Bela nos vai atraindo para o espetáculo final: a apoteose suicida do seu exibicionismo. Actriz do seu ser mítico de que está assombrada, Bela representase como diva do simbolizante feminino" (CORREIA, 1982, p. 9).

20 "Uma poesia maquilhada com langores de estrela de cinema mudo. [...] Uma cadelinha de luxo acarinhada no chá-das-cinco das senhoras do Modas e Bordados e do Portugal Feminino. [...] Sacerdotisa do Eterno feminino, Florbela automarginaliza-se desses vanguardismos que parecem desmanchar as antiguidades poéticas" (CORREIA, 1982, p. 10). 


\section{O IMANE: A REPRESENTAÇÃO DO MASCULINO NO PAI, NO IRMÃO, NOS MARIDOS E NOS AMANTES}

O termo imane ou imano parece derivar do latim immãne, tendo como significado bestial, imenso e, em última análise, aquele para quem foi atribuído ou acrescentado grande poder. Destacaremos aqui a proximidade do termo com o modelo, o exemplo, o herói das narrativas homéricas, como os personagens Aquiles, Heitor ou Ulisses ${ }^{21}$. A respeito do herói de obras literárias europeias, afirma Mircea Eliade que a pessoa ou "A personagem histórica é assimilada ao modelo mítico (herói etc.)" (ELIADE, 1992, p. 58). De acordo com o mesmo autor, o individual humano cede lugar à idealização do herói descomunal, o exemplar, o empoderado, o engrandecido. Vale lembrar aqui as palavras de Barbara Koltuv sobre a construção da imagem masculina na sociedade ocidental: "Devido à supervalorização cultural do masculino e à desvalorização do feminino, as mulheres frequentemente ficam desapontadas" (KOLTUV, 1997, p. 57). No soneto "Ambiciosa", Florbela Espanca registra o complexo processo de enamoramento e sucessiva decepção na interação entre a vestal feminina e o imane masculino. A seguir, citaremos apenas alguns versos:

21 Sobre a reminiscência da glorificação do personagem Ulisses no imaginário coletivo português e na obra poética de Fernando Pessoa, remeto à minha análise do poema pessoano "Ulysses", no livro A mensagem poética de Fernando Pessoa (2016). 
Para aqueles fantasmas que passaram, Vagabundos a quem jurei amar, Nunca os meus braços lânguidos traçaram O vôo dum gesto para os alcançar...

O amor dum homem? - Terra tão pisada! Gota de chuva ao vento baloiçada... Um homem? - Quando eu sonho o amor dum deus!... (ESPANCA, 1996, p. 234)

Na obra florbeliana a representação masculina é frequentemente elevada à condição de um herói. Entretanto, o sujeito poético se decepciona em seguida, pois são fantasmas, vagabundos, meros homens quando o sujeito desejante narcísico e insatisfeito sonha com o amor dum deus. Afirma B. Koltuv que a mágoa primitiva da mulher inicia no momento do contato com o corpo alheio da mãe, que não pudera ou não quisera amá-la. A frustração e descontentamento gera a busca incessante pelo encontro do amor correspondido: "Naturalmente essas jovens mulheres se voltaram, famintas de amor, para os pais e, mais tarde, para os amigos e maridos, de modo excessivamente compensatório" (KOLTUV, 1997, p. 57). Do embate com o masculino podem surgir novas decepções ${ }^{22}$, como se constata nos versos florbelianos supracitados. Do mesmo

22 "Consumados a paixão e o desejo, apenas Ihe resta a cinza, o resíduo da fruição sexual de todos os seus sonhos em geral e, mais especificamente, a lembrança de um momento inesquecível que a incita a um perpétuo recomeço na eterna procura de breves instantâneos de exaltação. Esta exaltação não advém do amante, mas do sentimento de plenitude alcançado através da consumação dos seus desejos de mulher" (MARTINS, 1990, p. 25). 
modo como declara o poeta brasileiro Mário Quintana, posiciona-se Florbela Espanca "Entre os Loucos, os Mortos [...] É lá que canto" (QUINTANA, 2008, p. 28).

Escreve Florbela Espanca sobre o momento de exaustão causada pelos enfretamentos e jogos de sedução do feminino com o imane, os vagabundos, os fantasmas, os loucos e os mortos. Do reflexo no espelho narcísico em que se constitui sua literatura, a escritora extrai inspiração para textos nos quais se define como a Maria das Quimeras, a Princesa Desalento, a Pobrezinha ${ }^{23}$. Ávida pela correspondência amorosa, a vestal não se submete, mas ocasionalmente volta a acreditar em um Prince Charmant. Encontra-se diante do imane, que se apresenta como herói, mas o que se percebe não é uma postura submissa como o título do poema "De joelhos" poderia sugerir. Lê-se, ao contrário, a exaltação do sagrado feminino:
De joelhos
"Bendita seja a Mãe que te gerou."
Bendito o leite que te fez crescer.
Bendito o berço aonde te embalou
A tua ama, pra te adormecer!
Bendita essa canção que te acalentou
Da tua vida o doce alvorecer...
Bendita seja a lua que inundou
De luz, a terra, só para te ver...

23 Título de poesias de Florbela Espanca. 
Benditos sejam todos os que te amarem, As que em volta de ti ajoelharem, Numa grande paixão fervente e louca!

E se mais que eu, um dia, te quiser Alguém, bendita seja essa Mulher. Bendito seja o beijo dessa boca!! ${ }^{24}$ (ESPANCA, 1996, p. 152)

A consagração do feminino é perceptível no soneto referido, sobretudo no emprego de palavras como Mãe e Mulher, em maiúsculas, além de ama e outras imagens poéticas representativas de feminilidade no campo semântico florbeliano, como lua, terra etc. Muitos textos florbelianos em poesia e prosa possuem a extrema e inegável revalorização do feminino. Lamentavelmente, não poderemos reproduzir todos aqui, e, por isso, utilizamos apenas "De joelhos" para exemplificar.

O par antitético (a vestal e o imane) emerge inicialmente das relações familiares de Florbela Espanca com o pai e o irmão Apeles, ecoando em seus relacionamentos com os maridos e amantes. Os homens "São o ninguém masculino na ordem secreta da Mulher Primordial. É sob este prisma mítico que se ateia o clarão em que Bela, a Bela do baile dos seus fantasmas, nos aparece" (CORREIA, 1982, p. 14). No Diário do último ano, livro de Florbela Espanca, "soa a hora marcada para ela entrar na urna de vidro. Poderemos

24 Mantivemos as aspas, grafia e pontuação do poema, publicado em Espanca, 1996, p. 152. 
vê-la, então, à transparência" (CORREIA, 1982, p. 14). Como a Bela Adormecida ou a Branca de Neve envenenada, representações do feminino nos contos de fadas europeus, em seu diário, cuidadosamente elaborado em tom confessional, o sujeito poético (d)escrito por Florbela Espanca é a mulher desfalecida na redoma de vidro, em permanente exposição para ser contemplada pelo imane masculino, mas, ainda assim, inatingível. Permanece aquela vestal virgem, pois "Todos os que, devassando-Ihe o corpo, não tocam no sacrum da virgindade ôntica do ser feminino" (CORREIA, 1982, p. 14).

A primeira representação do feminino com que Florbela Espanca interage é a mãe subalternizada em uma abstrusa relação com um homem casado, longa relação da qual nascem dois filhos ilegítimos: Florbela ${ }^{25}(8 / 12 / 1894)$ e o irmão Apeles (10/3/1897). Antónia da Conceição Lobo era empregada como criada de servir na casa de João Maria Espanca, que assumiu a paternidade de Florbela somente 19 anos depois do falecimento da escritora já famosa. A mãe de Florbela Espanca experimentou todo o preconceito e rejeição de uma relação adúltera e escandalosa na pequena cidade de Vila Viçosa, em Alentejo, no interior de Portugal. Parecenos que a mãe dos irmãos Espanca nunca demonstrou ou

25 Batizada como Flor Bela Lobo, adota mais tarde o nome Florbela d'Alma da Conceição Espanca. 
pode demonstrar qualquer interesse em educar os filhos, negando-Ihes o amor materno ${ }^{26}$.

Para complicar ainda mais o cenário familiar dramático ${ }^{27}$, Florbela Espanca foi criada desde a infância por Mariana do Carmo Toscano, esposa do seu pai. Muitos biógrafos de Florbela Espanca afirmam que a consorte sabia dos amores ilícitos do marido e, apesar disso, aceitou os filhos ilegítimos em sua casa. Se assim foi, a outra representação do feminino a qual Florbela Espanca foi exposta desde a primeira infância era igualmente subalternizada: a mulher estéril que acolhe (voluntariamente ou não) os filhos do imane.

A vida pessoal de Florbela Espanca foi extremamente conturbada e psicologicamente marcada pela depressão desde a infância e pelo interminável escândalo familiar. Os seus sucessivos casamentos ${ }^{28}$, pedidos de divórcio, amantes ${ }^{29}$

26 M. das Graças Orge Martins é uma das pesquisadoras que estudou as complexas relações familiares de Florbela Espanca e afirma: "Florbela jamais conheceria o amor da sua mãe natural" (MARTINS, 1990, p. 6).

27 A respeito da dinâmica familiar florbeliana, recuperamos aqui as ideias de L. Elia: "sem a ordem familiar e social, o ser da espécie humana morrerá. A essa condição Freud deu o nome de desamparo fundamental (Hilflosigkeit) do ser humano, que exige a intervenção de um adulto próximo (Nebenmensch) que penetre a ação específica necessária à sobrevivência do ser humano desamparado" (ELIA, 2010, p. 39, grifos do autor). Os irmãos Espanca viveram sem amor e reconhecimento familiar durante toda a vida.

28 Florbela casou-se com o professor Alberto de Jesus Silva Coutinho (1913-1920), enquanto a escritora cursava Letras e Direito, em Lisboa. No ano seguinte casou-se com seu amante António Guimarães (1921-1925), alferes de Artilharia. Seu terceiro e último marido foi o médico Mário Lage (1925-1930).

29 Casou-se com um deles, António Guimarães, depois do divórcio escandaloso com Alberto de J. S. Coutinho, por abandono de lar. 
e gravidez interrompida ${ }^{30}$ geraram muitos questionamentos na sociedade conservadora da época, igualmente atônita com as suspeitas de incesto entre os irmãos Florbela e Apeles. Não encontramos evidência comprobatória e inegável da relação incestuosa entre os irmãos, mas a mera suspeita alimentou boatos que mergulharam o nome Espanca no acervo das polêmicas interioranas. Parece-nos correto o que escreve M. Martins:

Sobre as peculiares relações entre os irmãos Espanca muito se tem especulado e alguns ousaram mesmo insinuar que entre ambos se teria estabelecido uma relação de natureza incestuosa ou que existiria, pelo menos, uma atracção não apenas espiritualmente fraternal, mas também física. Não obstante a especulação antes referida, certo é que a unir Apeles e Florbela existiria sempre um forte sentimento de solidariedade e de cumplicidade. (MARTINS, 1990, p. 6)

Solidariedade e cumplicidade entre irmãos que Florbela Espanca registra ainda melhor em prosa, no excruciante livro As Máscaras do Destino, publicado postumamente em 1931. No Prefácio à obra referida, Agustina Bessa Luís escreve que "existe um sentimento muito vivo da recriação da ilusão masculina e, ao mesmo tempo, um sentimento feminino de

30 Florbela Espanca não teve filhos, mas há registro de "gravidez inconsequente" (MARTINS, 1990, p. 7). 
culpa" (BESSA LUÍS, 1981, p. 17). São contos florbelianos nos quais as máscaras são depostas, uma a uma. A obra As Máscaras do Destino possui dedicatória "A meu irmão, ao meu querido morto", assim, em letras maiúsculas. Em seguida, Florbela Espanca escreve: "À querida alma irmã da minha, ao meu Irmão" (ESPANCA, 1981, p. 31). E mais claramente: "Mas eu não queria, não queria que o meu morto morresse comigo, não queria! E escrevi estas páginas..." (ESPANCA, 1981, p. 32). A extensa dedicatória registra o desamparo, a melancolia e a última decepção de Florbela Espanca com o imane, seu irmão suicida, que partira antes dela ${ }^{31}$.

O artista plástico e tenente Apeles Demóstenes da Rocha Espanca morreu em Lisboa aos 30 anos, quando o avião que pilotava foi arremessado no rio Tejo, em 6 de junho de 1927. Apeles e Florbela Espanca já tinham atentado contra suas vidas anteriormente, sendo registrada em apontamentos médicos a tentativa da escritora em 1928, resultante de uma grave crise de neurose ${ }^{32}$. Para silenciar os boatos de um pacto

\footnotetext{
31 Relembramos as palavras de André Malraux, em sua obra A condição humana: "Quando dizia que se mataria, não acreditava nisso; mas, já que ela acreditava, ele entrava num mundo onde a verdade não mais existia. O mundo cessara de pesar sobre ele" (MALRAUX, 1998, p. 238).

32 A frágil saúde física e mental de Florbela Espanca é assim descrita por sua biógrafa mais respeitada, Agustina Bessa Luís: "Todas as suas perturbações, a emoção exaltada, o esgotamento, as insónias, a intolerância aos alimentos, às pessoas, ao género de vida, a tuberculose encoberta, as dores de cabeça, as infecções, toda a espécie de repugnâncias físicas e morais, anunciam a instalação de neurose" (BESSA LUIS, 1984, p. 46).
} 
suicida entre os irmãos, além da suposição de uma relação incestuosa, oficialmente, as causas da morte são naturais. “Porém, a esta versão muitos contrapõem a hipótese de suicídio, argumentando com as tendências suicidas da autora que em Agosto de 1928 atentara, pela primeira vez, contra a sua própria vida (MARTINS, 1990, p. 9).

\section{COMENTÁRIOS FINAIS}

Florbela tornava-se uma escritora conhecida no cenário modernista português, quando faleceu no ano de 1930, no mesmo dia em que nasceu, 8 de dezembro. Dependente de Veronal, barbitúricos e outros medicamentos, Florbela Espanca pediu para não ser incomodada na noite anterior ao seu aniversário. Foi encontrada morta em seu quarto no dia seguinte, por seu marido e seu médico, Mário Lage. "Se momento algum da sua complexa biografia dispensou polémica, a sua morte não poderia desrespeitar tal princípio", afirma M. Martins (MARTINS, 1990, p. 9). Não se sabe ao certo quantas tentativas de suicídio existiram, mas irmanouse também nisso com Apeles que é, além do destinatário da sua obra As Máscaras do Destino, o personagem principal do conto "O aviador": "É um homem. Deixou lá em baixo ${ }^{33}$ todo o fardo pesado e vil com que o carregaram ao nascer" (ESPANCA,

33 Mantivemos a grafia original da palavra embaixo. 
1981, p. 39). Ainda que se recuse o excesso de biografismo ${ }^{34}$, reconhecemos que o encontro da vestal ${ }^{35}$ com o imane no contexto familiar e nos relacionamentos com maridos abusivos e amantes oportunistas podem ecoar na escrita melancólica e decadentista de Florbela Espanca, sobretudo nos últimos anos de vida, depois da morte de seu irmão.

Amar um homem é um gesto mágico para Florbela. Ela procura atingir um estado de euforia e de inspiração, através de sucessivos enamoramentos, procurando compensar assim o depauperamento narcísico que um dia não encontrará mais estímulos. (BESSA LUÍS apud ESPANCA, 1990, p. 25)

Em outra obra, esclarece Agustina Bessa Luís que "A poesia, representação simbólica do conteúdo do inconsciente, é afetada" (BESSA LUÍS, 1989, p. 50), pois a arte psicopatológica é uma das reminiscências modernistas da literatura confessional, como o Livro do Desassossego, de Bernardo Soares, semi-heterônimo de Fernando Pessoa e o Diário do último ano de Florbela Espanca. Ressalta M. da Graça Orge Martins que "é este, afinal, o conceito florbeliano de escrita, um acto de descoberta, de amor e de sofrimento, ou, melhor, um tormento delicioso, um "inquieto

\footnotetext{
34 Abordagem da obra literária a partir da biografia da autora.

35 "Surpreende-se, neste mimetismo mágico, a aspiração a uma concepção imaculada; o cerne inviolável da "amorosa sem luxúria", da "casta sem formalidades" intangível às posses de este e aquele e o outro e toda a gente" (CORREIA, 1982, p. 14).
} 
inebriamento" (MARTINS, 1990, p. 21). Por conseguinte, o espelho em que se contempla Florbela Espanca seriam seus textos, em desdobramentos literários que refletem o feminino narcísico e confessional, perceptíveis em sua obra e em última análise, igualmente em sua biografia.

\section{REFERÊNCIAS}

AMORA, Antônio S. Introdução à teoria da literatura. São Paulo: Cultrix, 1970.

BARROSO, Ivo. In: MALRAUX, André. A condição humana. Tradução e prefácio de Ivo Barroso. Rio de Janeiro: Record, 1998.

BESSA LUÍS, Agustina. Florbela Espanca. Lisboa: Guimarães Editores, 1984.

BRAIT, Beth. A personagem. 8. ed. São Paulo: Ática, 2006.

BRANDÃO, Luis Alberto. Grafias da identidade: literatura contemporânea e imaginário nacional. Rio de Janeiro/Belo Horizonte: Lamparina Editora/ Fale (UFMG), 2005.

BULFINCH, Thomas. O livro de ouro da mitologia (a idade das fábulas): histórias de deuses e heróis. Tradução de David Jardim Júnior. 9. ed. Rio de Janeiro: Ediouro, 2000.

CAVALCANTI, Raïssa. O mito de Narciso: o herói da consciência. São Paulo: Edições Rosari, 2003.

CORREIA, Natália. In: ESPANCA, Florbela. Diário do último ano, seguido de um poema sem título. Edição fac-similada com Prefácio de Natália Correia. Amadora: Bertand, 1982.

DAL FARRA, Maria Lúcia. In: ESPANCA, Florbela. Afinado desconcerto (contos, cartas, diário). São Paulo: Iluminuras, 2002.

DAL FARRA, Maria Lúcia. In: ESPANCA, Florbela. À margem dum soneto/O resto é perfume. Posfácio e fixação de texto por Maria Lúcia Dal Farra. Rio de Janeiro: 7Letras, 2007. 
DAL FARRA, Maria Lúcia. In: ESPANCA, Florbela. Poemas de Florbela Espanca. São Paulo: Martins Fontes, 1997.

DETIENNE, Marcel. A identidade nacional, um enigma. Tradução de Fernando Scheibe. Belo Horizonte: Autêntica, 2013.

EAGLETON, Terry. Depois da teoria: Um olhar sobre os Estudos Culturais e o pós-modernismo. 2. ed. Tradução de Maria Lúcia Oliveira. Rio de Janeiro: Civilização Brasileira, 2010.

ELIA, Luciano. O conceito de sujeito.3. ed. Rio de Janeiro: Jorge Zahar Ed., 2010.

ELIADE, Mircea. Aspectos do mito. Tradução de Manuela Torres. Lisboa: Edições 70, 1989.

ELIADE, Mircea. Mito e realidade. Tradução de Polla Civelli. São Paulo: Perspectiva, 2007.

ELIADE, Mircea. $O$ mito do eterno retorno: arquétipos e repetição.

Tradução de Manuela Torres. Lisboa: Edições 70, 1992.

ESPANCA, Florbela. Afinado desconcerto (contos, cartas, diário).

Organização de Maria Lúcia Dal Farra. São Paulo: Iluminuras, 2002.

ESPANCA, Florbela. À margem dum soneto/O resto é perfume. Posfácio e fixação de texto por Maria Lúcia Dal Farra. Rio de Janeiro: 7Letras, 2007. ESPANCA, Florbela. As Máscaras do Destino. Prefácio de Agustina Bessa Luís. 4. ed. Amadora: Bertrand, 1981.

ESPANCA, Florbela. Diário do último ano, seguido de um poema sem título. Edição fac-similada com Prefácio de Natália Correia. Amadora: Betrand, 1982.

ESPANCA, Florbela. $O$ dominó preto. Introdução de Fabio Mario da Silva. São Paulo: Martin Claret, 2010.

ESPANCA, Florbela. Poemas de Florbela Espanca. Estudo Introdutório, Organização e Notas de Maria Lúcia Dal Farra. São Paulo: Martins Fontes, 1997.

ESPANCA, Florbela. Sonetos. Introdução por M. da Graça Orge Martins. Lisboa: Ulisseia, 1990. 
FREITAS, Zilda de Oliveira. A mensagem poética de Fernando Pessoa. Lisboa: Chiado, 2016.

JUNQUEIRA, Renata Soares. Florbela Espanca: uma estética da teatralidade. São Paulo: Editora UNESP, 2003.

OSABAKE, Haquira. Prefácio In: JUNQUEIRA, Renata Soares. Florbela Espanca: uma estética da teatralidade. São Paulo: Editora UNESP, 2003. KOLTUV, Barbara B. A tecelã. Ensaios sobre a Psicologia Feminina Extraídos dos Diários de uma Analista Junguiana. Tradução de Eliane F. Pereira. São Paulo: Cultrix, 1997.

MAFFESOLI, Michel. No fundo das aparências. Tradução de Bertha H. Gurovitz. Petrópolis, RJ: Vozes, 1996.

MALRAUX, André. A condição humana. Tradução e Prefácio de Ivo Barroso. Rio de Janeiro: Record, 1998.

MARTINS, M. da Graça Orge. In: ESPANCA, Florbela. Sonetos. Introdução por M. da Graça Orge Martins. Lisboa: Ulisseia, 1990.

PAES, José Paulo. A aventura literária: Ensaio sobre ficção e ficções. São Paulo: Companhia das Letras, 1990.

QUINTANA, Mário. 80 anos de poesia. Seleção e organização de Tania F. Carvalhal. 13. ed. São Paulo: Globo, 2008.

SILVA, Fabio Mario da. In: ESPANCA, Florbela. O dominó preto. Introdução de Fabio Mario da Silva. São Paulo: Martin Claret, 2010. VILA MAIOR, Dionísio. Introdução ao modernismo. Coimbra: Almedina, 1996.

Zilda de Oliveira Freitas

Doutora em Estudos Portugueses pela Universidade Aberta de Portugal (UAb).

Professora da graduação e Pós-graduação na Universidade Estadual do Sudoeste da Bahia (UESB) - campus Jequié.

Coordena o "Grupo de Pesquisa e Extensão em Literatura" (GPEL) e o Programa Estação da Leitura (Estale), ambos na UESB.

http://lattes.cnpq.br/0330805407919089

https://orcid.org/0000-0002-0865-9489

zfreitas@uesb.edu.br 